\title{
Apoptosis is a major mode of cell death caused by ischaemia and ischaemia/reperfusion injury to the rat intestinal epithelium
}

\author{
H Ikeda, Y Suzuki, M Suzuki, M Koike, J Tamura, J Tong, M Nomura, G Itoh
}

\begin{abstract}
Background and aims-Injuries caused by ischaemia and ischaemia/reperfusion in the small intestine have been widely accepted as resulting in necrosis. The aim of this study was to ascertain whether apoptosis also occurs.

Methods-Intestinal epithelium from rats subjected to ischaemia (15-90 minutes) and ischaemia/reperfusion (15 minutes ischaemia followed by 15-75 minutes of reperfusion) was studied using histological, immunohistochemical, and molecular biological methods as well as FACS.

Results-Mucosal injury was induced by both ischaemia and ischaemia/reperfusion. Detachment of epithelial cells from the villous stroma was an early morphological change indicating mucosal injury. More than $80 \%$ of the detached cells exhibited characteristic morphological features of apoptosis (condensation of chromatin and nuclear fragmentation). The remainder demonstrated necrotic features. The apoptotic cells eventually underwent spontaneous degeneration with membrane rupture, a process morphologically identical to necrosis. DNA fragmentation was also confirmed by immunohistochemical methods and agarose gel electrophoresis.

Conclusion-Apoptosis is a major mode of cell death in the destruction of rat small intestinal epithelial cells induced by ischaemia and ischaemia/reperfusion injury. Disruption of epithelial cell-matrix interactions ("anoikis") may play an important part in induction of apoptosis in detached enterocytes.

(Gut 1998;42:530-537)
\end{abstract}

First Department of Pathology, Aichi Medical University, Nagakute-cho, Aichi-gun, Aichi-ken 480-1195, Japan

H Ikeda

Y Suzuki

M Suzuki

M Koike

J Tamura

J Tong

M Nomura

G Itoh

Correspondence to: Dr Ikeda.

Accepted for publication 9 October 1997
Keywords: ischaemia; reperfusion; apoptosis; necrosis; enterocyte; rat

Cell number in adult tissues is determined by the balance between cell production and cell loss. In recent years the idea that apoptosis is a common mechanism for regulating cell loss has become well established. ${ }^{1-3}$ In the gastrointestinal tract apoptosis is also reported to be important in physiological cell renewal. ${ }^{45}$ Recently, evidence has accumulated indicating that apoptosis is triggered by ischaemia and ischaemia/reperfusion. ${ }^{67}$ We have previously reported that human ischaemic myocardial injuries known as coagulation necrosis and contraction band necrosis feature distinct internucleosomal cleavage of DNA, ${ }^{8}$ demonstrated by the TUNEL method ${ }^{9}$ and agarose gel electrophoresis. ${ }^{10}$ The intestinal mucosa is probably one of the most sensitive tissues to ischaemia and ischaemia/reperfusion injury in the body. ${ }^{11}$ Standard textbooks of pathology state that mucosal injuries induced by circulatory disorders result in necrosis. ${ }^{12} 13$ Although the sequence of development of intestinal mucosal injury after ischaemia and reperfusion has been studied intensively, most studies have focused on the relatively late phase. ${ }^{14-16}$ Thus, early morphological changes indicative of mucosal injury, such as detachment of epithelial cells from the villous stroma, have not been studied in detail. Furthermore, Frisch and Francis have proposed that interactions between the matrix and cells are critical to regulation of apoptosis. ${ }^{17}$ This raises questions as to the mechanism of intestinal epithelial cell death induced by ischaemia and ischaemia/ reperfusion injury.

In the present study we have performed a detailed morphological and molecular biological analysis of epithelial cell death in rat small intestine induced by ischaemia and ischaemia/ reperfusion injury.

\section{Methods}

ISCHAEMIA AND ISCHAEMIA/REPERFUSION INJURY Six week old female Wistar rats (Japan SLC Inc, Hamamatsu) were used in this study. The animals were fasted for 18 hours before commencing the experiments but had free access to water. Pentobarbital sodium solution (Abbott Laboratories, North Chicago, Illinois, USA) $(30-40 \mathrm{mg} / \mathrm{kg})$ was administered into the intraperitoneal cavity to induce anaesthesia. All procedures were performed with the animals breathing spontaneously.

The rats were divided into three experimental groups undergoing (1) sham ischaemia $(\mathrm{n}=$ $10)$; (2) ischaemia $(\mathrm{n}=40)$; and (3) ischaemia/ reperfusion $(n=40)$. Through a midline abdominal incision, the superior mesenteric artery (SMA) was occluded for 15 minutes with an atraumatic vascular clamp. In order to block any collateral blood supply from the right colic and jejunal arteries, we used the procedure developed by Megison et al. ${ }^{18}$ The control animals underwent the same procedure except for the clamping of the SMA. Heparin $(1000 \mathrm{U} / \mathrm{kg})$ was injected intravenously at the time of mesenteric ischaemia. At the end of the ischaemic period the clamp was removed to allow reperfusion. A preliminary experiment revealed that both 15 minutes and 30 minutes 
of ischaemia followed by reperfusion induced epithelial destruction. However, it was noted that 30 minutes of ischaemia alone also induced epithelial destruction and DNA fragmentation, in contrast to 15 minutes ischaemia which did not cause any detectable injury. Thus, we applied 15 minutes of ischaemia followed by reperfusion for various time periods.

HISTOLOGICAL AND ELECTRON MICROSCOPICAL ASSESSMENT

After mesenteric ischaemia or sham ischaemia for 15, 30, 60 and 90 minutes and 15, 30, 45, 60 and 75 minutes of reperfusion, the small intestines were harvested. Two $\mathrm{cm}$ segments of the jejunum were resected and immediately fixed in $20 \%$ buffered formalin. The tissue was then embedded in paraffin wax, sectioned serially, and stained with haematoxylin and eosin. Histological mucosal damage in each preparation was graded on the six point scale defined by Chiu et $a l^{14}$ as follows: grade 0, normal mucosa; grade 1, development of subepithelial (Gruenhagen) spaces near the tips of the villi with capillary congestion; grade 2 , extension of the subepithelial space with moderate epithelial lifting from the lamina propria; grade 3 , significant epithelial lifting along the length of the villi with a few denuded villous tips; grade 4 , denuded villi with exposed lamina propria and dilated capillaries; and grade 5, disintegration of the lamina propria, haemorrhage, and ulceration. Data are presented as median and range. Significance was tested with the Sign test $^{19}$ within groups and the Wilcoxon rank test ${ }^{20}$ between groups. A p value of $<0.05$ was considered statistically significant.

For electron microscopy, small pieces of small intestine were fixed in $2 \%$ paraformaldehyde and $2.5 \%$ glutaraldehyde (Nisshin EM Co Ltd, Tokyo, Japan) in $0.05 \mathrm{~mol}$ phosphate buffer (PB) (pH 7.4) for two hours. After rinsing three times with $\mathrm{PB}$, samples were then stored in PB for 24 hours. The tissues were then routinely processed as reported previously. ${ }^{21}$

\section{HISTOCHEMICAL DETECTION OF DNA}

FRAGMENTATION

The terminal deoxynucleotidyl-transferase (TdT) mediated d-UTP-biotin nick end labelling (TUNEL) method $^{9}$ has been used as an approach to demonstrate DNA fragmentation. However, the effectiveness of the TUNEL method is greatly hampered by fixation, especially for the detection of apoptotic cells in gastrointestinal epithelium. We therefore used the method reported by Ichimura et al..$^{22}$ In brief, fresh specimens of small intestine were heated in a microwave to boiling in $20 \%$ buffered formalin and the fixation was continued overnight at room temperature to prevent a false positive reaction that may be attributed to exogenous and endogenous deoxyribonuclease I (DNase I) activity. The tissue was then embedded in paraffin wax and sectioned serially. After deparaffinisation and dehydration, tissue sections were stained using the TUNEL method as reported previously.
ASSESSMENT OF APOPTOSIS AND NECROSIS USING DNA BINDING FLUOROCHROMES AND ANNEXIN V To discriminate between apoptotic and necrotic cell death, the detached epithelial cells were examined using DNA binding fluorochromes, Hoechst 33342 (HO342) (Molecular Probes, Eugene, Oregon, USA) and propidium iodide (PI) (Molecular Probes). ${ }^{23}$ Furthermore, the frequencies of both apoptotic and necrotic cells were also analysed using FITClabelled Annexin V and PI (Apoptosis Detection Kit, R\&D Systems Inc, Minneapolis, USA). ${ }^{24}$ Resected segments of small intestine were washed vigorously in phosphate buffered saline (PBS) to collect the detached epithelial cells. After being pipetted and pelleted, the cells were resuspended in PBS $\left(10^{6}\right.$ cells $\left./ \mathrm{ml}\right)$, then divided into two samples. For the staining of $\mathrm{HO} 342$ and PI, cells were incubated at $37^{\circ} \mathrm{C}$ in the presence of $1 \mu \mathrm{g} / \mathrm{ml} \mathrm{HO} 342$ for $10 \mathrm{~min}$ utes. They were then cooled on ice, centrifuged, resuspended in PBS, exposed to PI of $5 \mu \mathrm{g} / \mathrm{ml}$ and kept on ice. Apoptotic and necrotic cells were identified using a fluorescence microscope (Nikon Labophoto, dichroic mirror B, excitation filter IF420-490, barrier filter 515W). For the staining of Annexin V and PI, cells $\left(1 \times 10^{5}\right)$ were stained using an apoptosis detection kit and were then analysed with a FACS Calibur (Becton Dickinson) as soon as possible. ${ }^{24}$

DETECTION OF DNA FRAGMENTATION OF INTESTINAL EPITHELIAL CELLS BY AGAROSE GEL ELECTROPHORESIS

DNA extraction and electrophoresis were performed by the methods described by Facchinetti et al. ${ }^{10}$ In brief, detached enterocytes were collected by centrifugation of PBS solution containing cells at $3000 \mathrm{rpm}$ for five minutes at $4^{\circ} \mathrm{C}$. The supernatant was discarded and the pellet containing the enterocytes was used for DNA extraction as reported previously. ${ }^{8}$

PERCENTAGE DNA FRAGMENTATION ASSAY

The extent of DNA fragmentation was determined by a modification of the method reported by Cohen and Duke. ${ }^{25}$ The whole epithelium of resected jejunum without the muscle layer was collected by mechanical scraping with a blade, pipetted vigorously in PBS, and harvested by centrifugation at 3000 rpm for five minutes. Pellets were lysed with $0.4 \mathrm{ml}$ hypotonic lysing buffer $(10 \mathrm{mmol}$ Tris, 10 mmol EDTA; pH 8.0) containing 0.5\% Triton X-100 (Katayama), and the lysates were centrifuged at $15000 \mathrm{rpm}$ for 20 minutes to separate intact DNA from fragmented chromatin. The supernatant, containing fragmented DNA, was placed in a separate microfuge tube and both fractions were precipitated for 30 minutes at $4^{\circ} \mathrm{C}$ in $0.5 \mathrm{~N}$ perchloric acid (Katayama). Precipitates were sedimented at $15000 \mathrm{rpm}$ for 20 minutes and the included DNA was hydrolysed by heating to $90^{\circ} \mathrm{C}$ for 10 minutes in $150 \mu \mathrm{l} 1 \mathrm{~N}$ perchloric acid and then quantified by a modification of the diphenylamine (DPA) method of Burton. ${ }^{26}$ The percentage of DNA fragmented was defined as the 

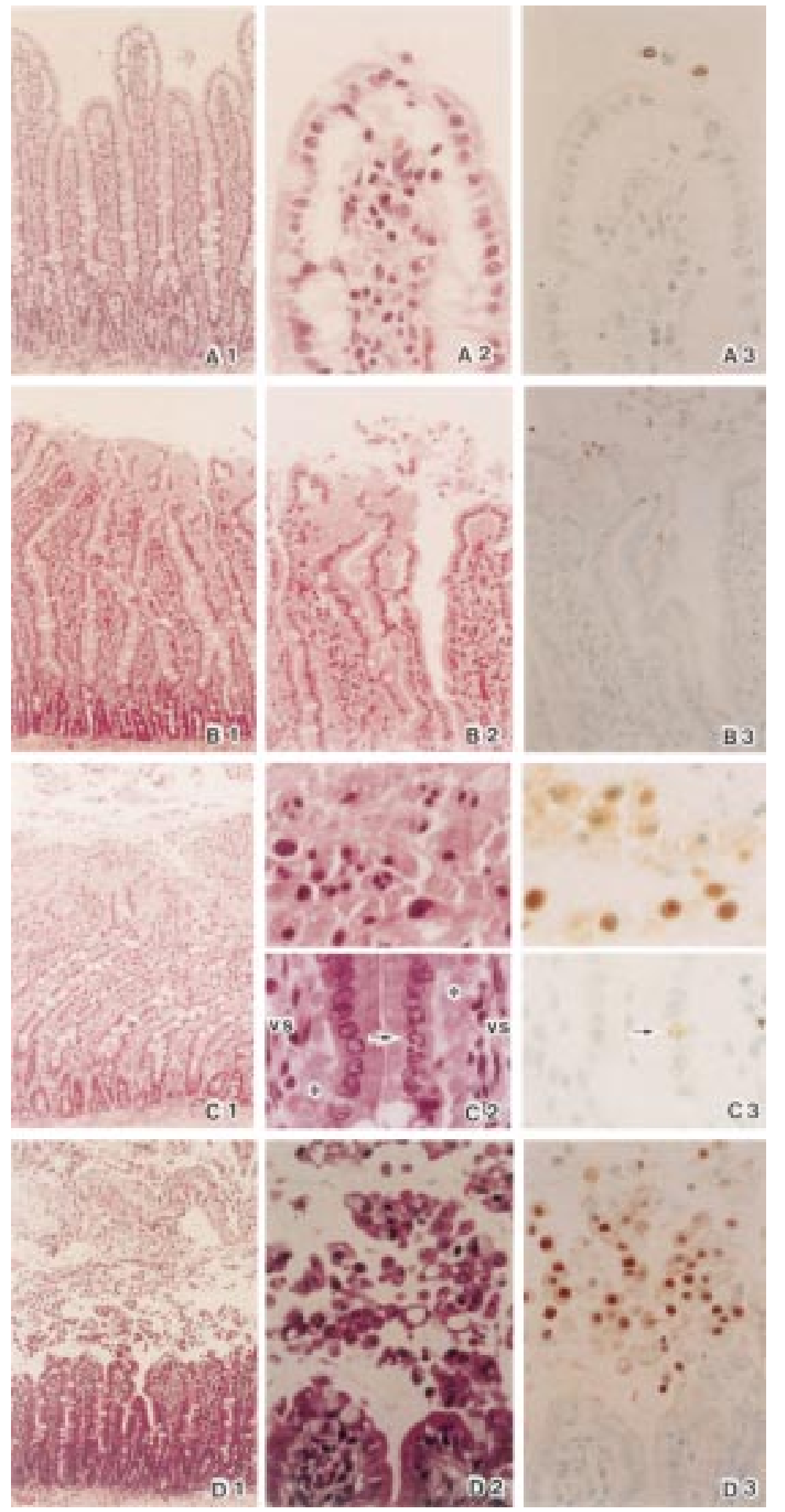

Figure 1 Sections of jejunum following ischaemia for 15 minutes (A1-3), 30 minutes (B1-3), and 60 minutes (C1-3), and in a group given 75 minutes' reperfusion followed by 15 minutes of ischaemia (D1-3). In A1-3 no significant changes are apparent except for dilatation of Gruenhagen's space. Apoptotic cells are present at the tip of the villi $(A 2,3)$. In B1-3 note the amorphous substance between the villous stroma and the base of the epithelial cells (B2). Some enterocytes are TUNEL positive (B3). In C1-3 the upper regions of the villi are destroyed. Many detached enterocytes show both condensed and fragmented nuclei which are TUNEL positive $(C 2,3)$. Some enterocytes located in the lower region, which are detached from the villous stroma, are also TUNEL positive (C2, 3 arrow). Note the amorphous substance (*) between the epithelium and villous stroma (vs) in C2. In D1-3 notable destruction of the upper two thirds of the villi is evident but the tips are covered with enterocytes after 75 minutes of reperfusion (D2). Most of the detached cells show condensed and fragmented nuclei and also TUNEL positive staining, in contrast to the enterocytes located in the villi (D3). Serial sections A1-D1 and A2-D2 were stained with haematoxylin and eosin and sections A3-D3 were stained using the TUNEL method. Original magnification: $\times 40(A 1-D 1), \times 100(B 2, B 3), \times 150(D 2, D 3), \times 200(A 2, A 3$, $C 2, C 3)$. ratio of the DNA content of the supernatant obtained at $15000 \mathrm{rpm}$ to the total DNA in the lysate.

\section{Results}

LIGHT AND ELECTRON MICROSCOPIC FINDINGS AND HISTOCHEMICAL DETECTION OF DNA FRAGMENTATION

After ischaemia of 15 minutes' duration or more, an increasing degree of mucosal injury was seen with the duration of the ischaemic period. Reperfusion after 15 minutes and 30 minutes of ischaemia also caused significant exacerbation of mucosal injury (table 1). The destruction of villi continued during the experiment in the ischaemia group but this was not the case for the reperfusion groups. Destructive changes had subsided within 75 minutes of reperfusion followed by 15 minutes of ischaemia, and 45 minutes of reperfusion followed by 30 minutes of ischaemia, respectively.

Fifteen minutes of ischaemia did not cause any detectable injury except for dilatation of the Gruenhagen's space in the upper region of the villi (fig 1, A1 and A2). After 30 minutes of ischaemia the mucosa was still largely preserved, but the enterocytes in the upper third of the villi had lifted from the villous stroma. Between the epithelium and the villous stroma there was amorphous material, some of which passed into the intestinal lumen through the dissociated enterocytes (fig 1, B1 and B2). After 60 minutes (fig 1, C1 and C2) and 90 minutes of ischaemia (data not shown) more prominent destruction with denuded villi and detached enterocytes was observed. Among the detached epithelial cells, many enterocytes exhibited both condensed and fragmented nuclei (fig 1, C2 and D2). DNA fragmentation of the damaged cells was examined by the TUNEL method. At the end of 15 minutes' ischaemia no enterocytes showed TUNEL positive staining except for cells at the tips (fig 1, A3). After 30 minutes' ischaemia, however, some enterocytes demonstrated a positive reaction (fig 1, B3) and after 60 minutes (fig 1 , C3) many of the detached enterocytes showed TUNEL positive staining. Furthermore, some enterocytes located in the lower part of the villi were also TUNEL positive (fig 1, C3).

In the reperfusion groups similar features of epithelial cell destruction, as evidenced by detachment and lifting down the sides of the villi, were observed. However, both the detachment of enterocytes and the destruction of the villous stroma had subsided after 75 minutes of reperfusion followed by 15 minutes of ischaemia (fig 1, D1). The detached cells had apoptotic features of condensed and fragmented nuclei (fig 1, D2) and showed TUNEL positive (fig 1, D3). However, this was not the case for all affected cells (fig 1, D3). Furthermore, enterocytes located at the villous tips were not TUNEL positive after 75 minutes of reperfusion (fig 1, D3).

Electron microscopic examination of epithelial cells after both ischaemia (fig 2B) and ischaemia/reperfusion (fig $2 \mathrm{C}$ ) revealed typical changes as shown in fig $1, \mathrm{C} 2$ and D2. The 
Table 1 Grades of mucosal injury after ischaemia and various reperfusion time peroids

\begin{tabular}{lllllll}
\hline \multicolumn{7}{l}{ Reperfusion after ischaemia (min) } \\
Group & 0 & 15 & 30 & 45 & 60 & 75 \\
\hline 15 min' ischaemia & $1(0-1)$ & $2(1-3)$ & $3(3-4)$ & $3(3-4)$ & $4(4-5)$ & $1(0-1)^{\star}$ \\
30 min' ischaemia & $2(1-3)$ & $4(4-5)$ & $4(4-5)$ & $1(0-1)^{\star}$ & $1(0-1)^{\star}$ & $1(0-1)^{\star}$ \\
60 min' ischaemia & $3(3-5)$ & - & - & - & - & - \\
90 min' ischaemia & $5(4-5)$ & - & - & - & - & $0(0-1)$ \\
Sham ischaemia & $0(0-1)$ & $0(0-1)$ & $0(0-1)$ & $0(0-1)$ & $0(0-1)$ & $0(0-1)$ \\
\hline
\end{tabular}

^Destructive changes subsided after 75 minutes' reperfusion followed by 15 minutes' ischaemia, and 45 minutes' reperfusion followed by 30 minutes' ischaemia, respectively.

amorphous substance seen by light microscopy consisted of blebs of various sizes situated between the epithelium and basement membrane (fig 2B). No apoptotic features were found in control intestinal epithelium (fig 2A) except at the tips of the villi.

ASSESSMENT OF APOPTOSIS AND NECROSIS USING DNA BINDING FLUOROCHROMES AND ANNEXIN V Fluorescence microscopical studies were carried out with differential $\mathrm{HO} 342$ staining of apoptotic versus viable cells as well as PI. In

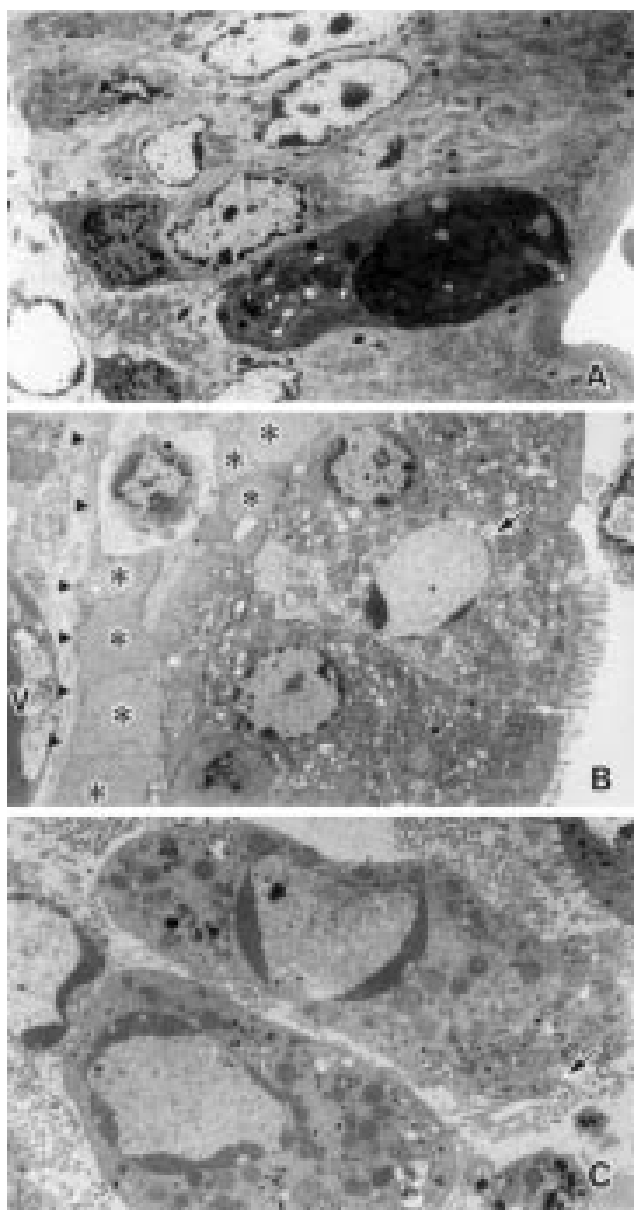

Figure 2 Electron microphotographs of jejunum from groups given $(A)$ sham ischaemia, (B) 90 minutes of ischaemia, and $(C) 45$ minutes of reperfusion. $(A)$ Enterocytes located in the middle part of the villi show no remarkable changes. (B) An enterocyte showing compaction and segregation of chromatin against the nuclear envelope (arrow) is observed between normal appearing cells. The amorphous substance is evident as blebs limited by a simple membrane ( ${ }^{*}$ ) (arrowhead, basement membrane; $V$, vessel). (C) Detached cells have characteristic features of apoptosis but still preserve microvilli (arrow) and intact mitochondria. Original magnification: $\times 2500$ ( $A$ and $B)$, $\times 5000(C)$. both the ischaemia (fig 3A) and ischaemia/ reperfusion groups (fig 3B) $\mathrm{HO} 342$ positive cells showed chromatin condensation patterns and the fragmented nuclei typical of apoptosis (fig 3A-D, large arrows). Some PI positive cells had oval and round nuclei (fig 3A-D, arrowheads) but others had condensed or fragmented nuclei (fig 3B, small arrows). The cells that had fragmented nuclei stained with HO342 demonstrated a round shape (fig 3D, arrow) in contrast to those with oval nuclei stained with PI which were relatively normal in terms of their morphology (fig 3D, arrowhead).

The frequencies of apoptotic and necrotic cells were analysed by FACS using an apoptosis detection kit (Vector Laboratories). ${ }^{24}$ The results revealed that both types of cell deaths occurred after ischaemia (fig 4A) and ischaemia/ reperfusion (fig $4 \mathrm{~B})$. The sorted $\mathrm{PI}^{\text {high }}$ cells $\left(\mathrm{G}_{1}\right.$ population) with FACS demonstrated oval or round nuclei and preservation of normal morphology (fig 3B, arrowheads). On the other hand, $\mathrm{PI}^{\text {low }}$ cells $\left(\mathrm{G}_{2}\right.$ population) were characterised by the apoptotic features of a round shape and fragmented nuclei (fig 3B, small arrows). Furthermore, TUNEL staining showed that the nuclei of $\mathrm{PI}^{\mathrm{low}}$ cells were positive while those of $\mathrm{PI}^{\text {high }}$ cells were negative (data not shown). These findings suggest that $\mathrm{PI}^{\text {low }}$ cells are late apoptotic, namely "secondary necrosis", while PI ${ }^{\text {high }}$ cells are necrotic. Thus, the $\mathrm{PI}^{\text {low }}$ population was counted as apoptotic cells in this study. Figure $4 \mathrm{C}-\mathrm{E}$ summarises data for the frequencies of each population. In the early phase 15 minutes' reperfusion was associated with a higher frequency of necrotic cells and a lower frequency of apoptotic cells than those subjected to 30 minutes' ischaemia (fig $4 \mathrm{E}$ ). At subsequent time points no significant difference was observed between the two regimens.

DETECTION OF DNA FRAGMENTATION IN INTESTINAL EPITHELIUM BY AGAROSE GEL ELECTROPHORESIS

DNA fragmentation in samples of small intestine obtained from the ischaemia and ischaemia/reperfusion groups was studied by agarose gel electrophoresis. ${ }^{8} 10$ Multiples of 180-200 bp subunits were detected in the 30 minute and 60 minute ischaemia groups, respectively (fig 5, lanes 1 and 2). Thereafter, cleavage of DNA was always clear, and was also evident after 45 minutes' reperfusion (fig 5, lane 3).

PERCENTAGE DNA FRAGMENTATION ASSAY In order to clarify whether the destruction process continued during the experimental period in both groups, the extent of DNA fragmentation 

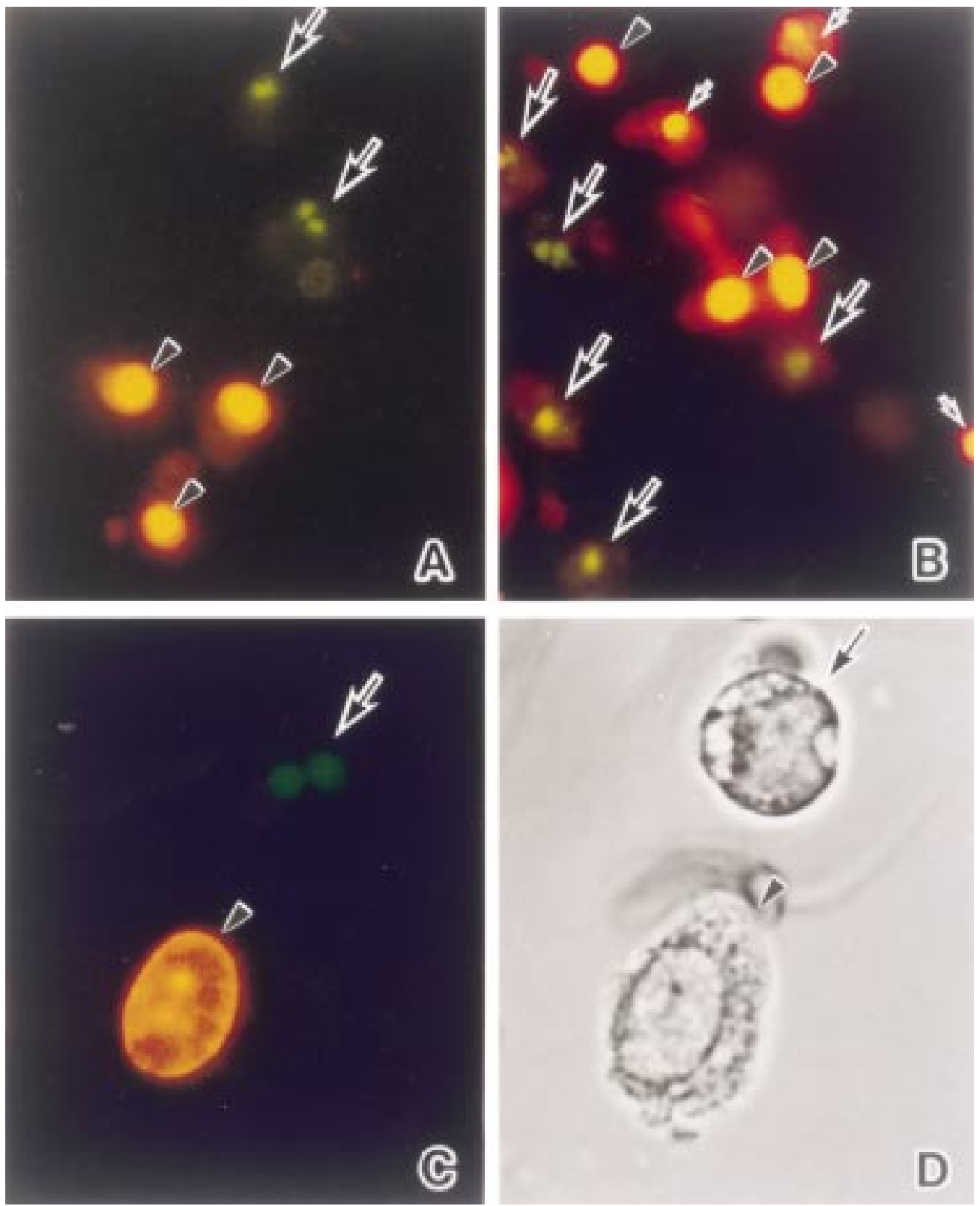

Figure 3 Fluorescence microphotographs of detached enterocytes stained with the DNA binding fluorochromes HO342 and PI: (A) 60 minutes' ischaemia, and (B) 45 minutes' reperfusion. (C) High power magnification of fig 3B. (D) Light microscopical finding for the cells in fig 3C. (A) Condensed and fragmented nuclei are $\mathrm{HO} 342$ positive (arrows) (green blue) in contrast to the PI positive oval or round nuclei (arrowheads) (red yellow). (B) Some condensed and fragmented nuclei are HO342 (large arrows) and others are PI (small arrows) positive. On the other hand, oval or round nuclei preserving their normal morphology are PI positive (arrowheads). (C) and (D) A HO342 positive cell with a fragmented nucleus has a round shape with apoptotic features (arrow) while a PI positive cell with an oval nucleus demonstrates a relatively normal morphology (arrowhead). Original magnification: $\times 80(A$ and $B), \times 160(C$ and $D)$.

of epithelial cells was studied (fig 6). The results revealed that the increase above background levels had begun in both the 30 minute ischaemia and 15 minute reperfusion groups with no significant difference between the two. Thereafter, the process continued with an increase in \% DNA fragmentation being observed up to the 90 minute time point.

\section{Discussion}

It is well known that the epithelial cell layer of the small intestine subjected to ischaemia alone or ischaemia/reperfusion becomes injured, resulting in necrosis. ${ }^{12} 13$ This study has provided the first evidence that two distinct modes of cell death - apoptosis and necrosis - are involved in the destruction of rat small intestinal epithelial cells. Furthermore, apoptosis was demonstrated to be the major mode. The methods used-light and electron microscopy, fluorescence microscopy with the DNA binding fluorochrome $\mathrm{HO} 342,{ }^{23}$ FACS analysis using Annexin V (apoptosis detecting kit), ${ }^{24}$ TUNEL staining, ${ }^{8} 922$ electrophoretic detection of DNA laddering, ${ }^{10}$ and the \% DNA fragmentation assay $^{25} 26$-all provided support for this conclusion. Necrosis evaluated by fluorescence microscopy and FACS using DNA binding fluorochrome $\mathrm{PI}^{2324}$ was, in comparison, relatively minor. 

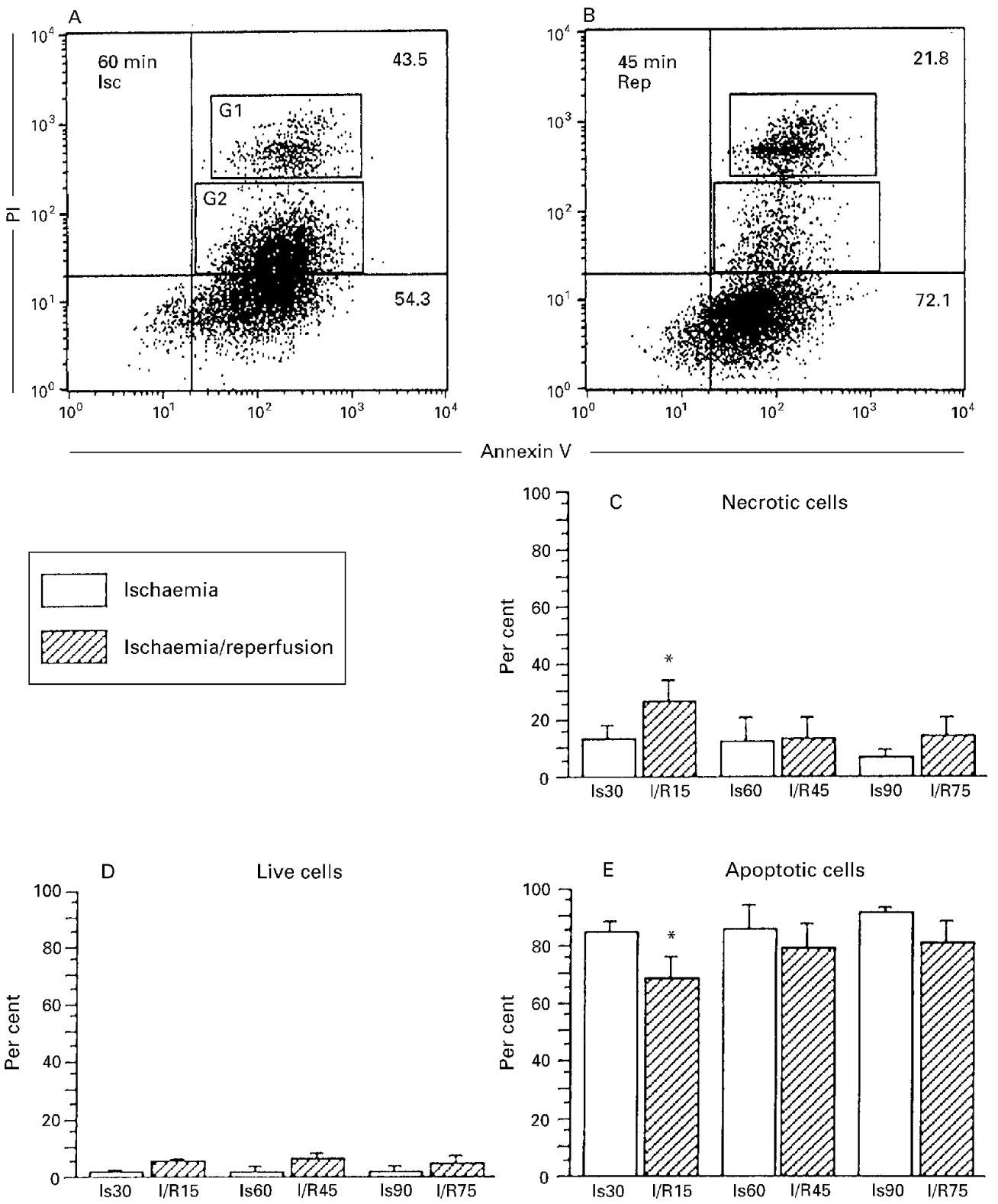

Figure 4 Flow cytometric analysis of FITC-Annexin V binding and PI uptake of detached enterocytes undergoing apoptosis versus necrosis. Detached enterocytes $\left(1 \times 10^{4}\right)$ were analysed after both ischaemia $(A)$ and reperfusion $(B)$. (C-E) Frequencies of live, necrotic, and apoptotic cells after ischaemia (30, 60, and 90 minutes) and reperfusion (15, 45, and 75 minutes). The lower left quadrant of each panel shows live cells (FITC-Annexin-/PI), the lower right quadrant represents apoptotic cells (FITC-Annexin $/ P I)$ and the upper right quadrant contains the non-viable, necrotic cells $\left(F I T C-\right.$ Annexin $\left.{ }^{+} / P I^{+}\right)$. These latter comprise both $P I^{\text {high }}$ cells $\left(G_{\nu}\right)$ and $P I^{\text {low }}$ cells $\left(G_{2}\right)$. $(A) P I^{\text {high }}$ cells have oval or round nuclei and preserve their normal morphology as in fig $3 B$ (arrowheads) and PI ${ }^{\text {low }}$ cells are round in shape with condensed and fragmented nuclei as in fig $3 B$ (small arrows). Numbers within the dot plots represent the percentages of cells in each quadrant. One representative experiment out of five is shown. More than $80 \%$ of the detached cells show apoptotic features $(C-E)$. Significant differences between the ischaemia and reperfusion groups were only observed for the early phase of the experiment. ${ }^{\star} p<0.01$ compared with 30 minutes' ischaemia.

Previous morphological studies of this area have not mentioned induction of apoptosis in rat small intestine subjected to ischaemia and ischaemia/reperfusion. ${ }^{14-16}$ They focused on the relatively late phase of ischaemia and ischaemia/reperfusion injury after more than one hour and the present histological results of ischaemia are similar to those previously reported. Park et $a l^{27}$ considered that ischaemia with a duration of less than 20 minutes did not induce mucosal injury, nor did they find any significant lesions due to reperfusion. Although the reason for the discrepancy between studies is not clear, differences in methodology might have played a role. If attention is not concentrated on detached epithelial cells, intestinal damage might be missed in the reperfusion group. With regard to the time required for reperfusion injury, 15 minutes followed by reperfusion was clearly sufficient in the present case. Thereafter, changes were progressive in terms of DNA fragmentation, although the destruction of the villi subsided during 75 minutes' reperfusion.

Wagner et al have reported that the characteristic feature of ischaemic damage to the small intestinal villous epithelium is the detachment of enterocytes from the basement 


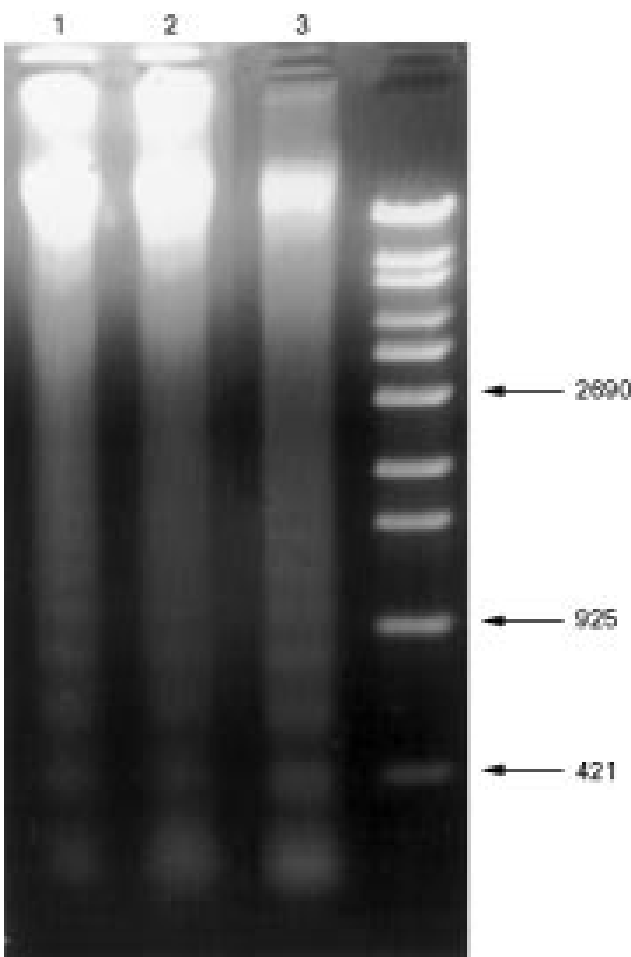

Figure 5 Agarose gel electrophoresis of DNA extracted from small intestine after 30 minutes (lane 1) and 60 minutes (lane 2) of ischaemia and 45 minutes of reperfusion (lane 3). Both the ischaemia (lanes 1 and 2) and ischaemia/reperfusion groups (lane 3) show ladder patterns.

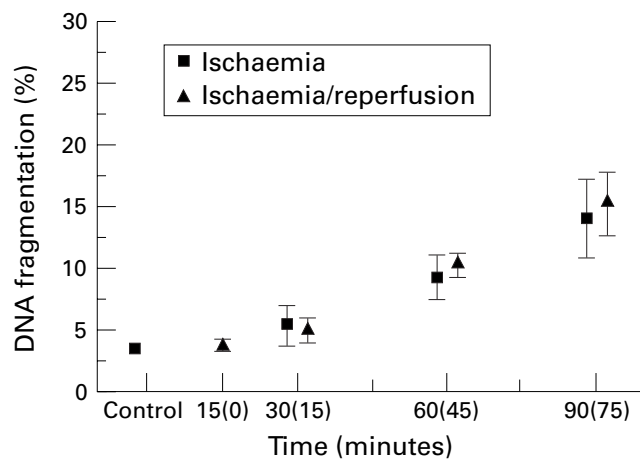

Figure 6 Time course of percentage DNA fragmentation after ischaemia and ischaemia/reperfusion. The percentage of fragmented DNA in the ischaemia and

ischaemia/reperfusion groups was measured at various time points. No significant differences between ischaemia and ischaemia/reperfusion injury were observed.

membrane. ${ }^{28}$ The intestinal mucosa shows the first morphological alteration at the tips of the villi after ischaemia of only 15 minutes, and this progresses to the base of the villi with continuation of the ischaemia. The reason for epithelial shedding is the appearance of membrane enclosed cytoplasmic blebs which arise at the cell base of the enterocytes and cause detachment from the basement membrane. ${ }^{28}$ Our data have shown that this was also a prominent feature of reperfusion injury followed by 15 minutes' ischaemia.

At present we can only speculate as to the mechanisms that induce apoptosis of detached enterocytes. Previous authors have reported alterations in cell adhesion molecules or substratum along the crypt-villous axis, and used this to support the idea of cell loss by shedding. For example, Beaulieu has proposed that altered expression of $\beta_{1}$ integrins along the crypt-villous axis facilitates cell loss. ${ }^{29}$ Probsteimer et al have argued that cell shedding at the villus tip is a consequence of changes in expression and function of $\mathrm{J} 1 /$ tenascin at the upper part of the villus. ${ }^{30}$ However, Frisch and Francis have recently proposed that interactions between extracellular matrix materials and cells play a critical role in apoptosis, ${ }^{17}$ cell death occurring when contacts are disrupted. This phenomenon has been called "anoikis." Our study has shown that affected epithelial cells lose their contact with the villous stroma and thus apoptosis induced by ischaemia and ischaemia/reperfusion could represent "anoikis." However, as revealed by our data, not all the detached cells demonstrate positive staining with the TUNEL method and some show evidence of necrotic cell death when examined by DNA binding fluorochromes PI.

In conclusion, apoptosis is the major form of cell death occurring after short term ischaemia or ischaemia/reperfusion in the rat jejunum. Distribution of epithelial cell-matrix interactions ("anoikis") may play an important part in induction of apoptosis in detached enterocytes.

This work was supported in part by the Murayama Foundation, by a grant-in-aid for a specific research project, and by a grant for research promotion from Aichi Medical University.

1 Kerr JFR, Wyllie AH, Currie AR. Apoptosis: a basic biologial phenomenon with wide implications in tissue kinetics. Br f Cancer 1972;26:239-57.

2 Raff MC. Social controls on cell survival and cell death. Nature 1992;356:397-400.

3 Coles HSR, Burne JF, Raff MC. Large scale normal cell death in the developing rat kidney and its reduction by epidermal growth factor. Development 1993;118:777-84.

4 Potten CS, Merritt A, Hickman J, et al. Characterization of radiation-induced apoptosis in the small intestine and its biological implications. Int $\mathcal{F}$ Radiat Biol 1994;65:71-8.

5 Potten CS, Wilson JW, Booth C. Regulation and significance of apoptosis in the stem cells of the gastrointestinal epithelium. Stem Cells 1997;15:82-93.

$6 \mathrm{Li} \mathrm{Y,} \mathrm{Sharov} \mathrm{VG,} \mathrm{Jiang} \mathrm{N,} \mathrm{et} \mathrm{al.} \mathrm{Ultrastructural} \mathrm{and} \mathrm{light}$ microscopic evidence of apoptosis after middle cerebral artery occlusion in the rat. Am f Pathol 1995;146:1045-51.

$7 \mathrm{Li} \mathrm{Y}$, Chopp M, Jiang N, et al. Induction of DNA fragmen$\mathrm{Li} \mathrm{Y}$, Chopp M, Jiang N, et al. Induction of DNA fragmentation after 10 to 120 minutes

8 Itoh G, Suzuki M, Suzuki Y, et al. DNA fragmentation of human infarcted myocardial cells demonstrated by the nick end labeling method and DNA agarose gel electrophoresis. Am f Pathol 1995;146:1325-31.

9 Gavrieli Y, Sherman Y, Ben-Sasson SA. Identification of programmed cell death in situ via specific labeling of nuclear DNA fragmentation. F Cell Biol 1992;119:493501.

10 Facchinetti A, Tessarollo M, Mazzocchi R, et al. An improved method for the detection of DNA fragmentation. f Immunol Methods 1991;136:125-31.

11 Haglund U. Gut ischemia. Gut 1994;35(suppl 1):73-6.

12 Cotran RS, Kumar V, Robbins S. The gastrointestinal tract. In: Cotran RS, Kumar V, Robbins S, eds. Robbins'pathologic In: Cotran RS, Kumar V, Robbins S, eds. Robbins'pathol
basis of disease. Philadelphia: Saunders, 1994:755-830.

13 Damis of disease. Philadelphia: Saunders, 1994:755-830. Linder J, eds. Anderson's pathology. St Louis: Mosby, 1996: Linder J,

14 Chiu CJ, McArdle AH, Brown R, et al. Intestinal mucosal lesion in low-flow states: a morphological, hemodynamic and metabolic reappraisal. Arch Surg 1970;101:478-83.

15 Stojadinovic A, Kiang J, Smallridge R, et al. Induction of heat-shock protein 72 protects against ischemia/ reperfusion in rat small intestine. Gastroenterology 1995; 109:505-15

16 Wagner R, Gabbert H, Höhn P. Ischemia and post-ischemic regeneration of the small intestinal mucosa. Virchows Arch 1979;31:259-76.

17 Frisch SM, Francis H. Disruption of epithelial cell-matrix interactions induces apoptosis. F Cell Biol 1994;124:61926.

18 Megison SM, Horton JW, Chao H, et al. A new model for intestinal ischemia in the rat. F Surg Res 1990;49:168-73.

19 Siegel S. Nonparametric statistics for the behavioral sciences. New York: McGraw-Hill, 1956.

20 Deam K, Lentner C. Scientific tables. Basle: Ciba-Geigy, 1971. 
21 Ikeda $\mathrm{H}$, Tauchi $\mathrm{H}$, Sato T. Fine structural analysis of lipofuscin in various tissues of rats of different ages. Mech Age-

22 Ichimura E, Fukuda T, Oyama T, et al. Formalin fixation by boiling: is it suitable for the TUNEL staining? Pathol Int 1995; 45:971-2.

23 Ormerod MG, Collins MKL, Rodriguez-Tarduchy G, et al. Apoptosis in interleukin-3-dependent haemopoietic cells. Quantification by two flow cytometric methods. F Immuno Methods 1993;153:57-65.

24 Vermes I, Haanen C, Nakken HS. A novel assay for apoptosis. Flow cytometric detection of phosphatidylserine expression on early apoptotic cells using fluorescence labeled annexinV. F Immunol Methods 1995;184:39-51.

25 Cohen JJ, Duke RC. Glucocorticoid activation of a calciumdependent endonuclease in thymocyte nuclei leads to cell death. F Immunol 1984;132:38-42.
26 Burton K. A study of the conditions and mechanism of the diphenylamine reaction for the colorimetric estimation of deoxyribonucleic acid. Biochem f 1956;62:315-23.

27 Park PO, Haglund U, Bulkley GB, et al. The sequence of development of intestinal tissue injury after strangulation ischemia and reperfusion. Surgery 1990;107:574-80.

28 Wagner R, Gabber H, Höhn P. The mechanism of epithelial shedding after ischemic damage to the small intestinal mucosa. A light and electron microscopic investigation. Virchows Arch 1979;30:25-31.

29 Beaulieu JF. Differential expression of the VLA family of integrins along the crypt-villus axis in the human small intestine. $\mathcal{F}$ Cell Sci 1992;102:427-36.

30 Probsteimer R, Martini R, Schachner M. Expression of $\mathrm{J} 1 /$ tenascin in the crypt-villus unit of the adult mouse small intestine: implication for its role in epithelial cell shedding. Development 1990;109:313-21. 